\title{
Industry 4.0: changes in work organization and qualification requirements-challenges for academic and vocational education
}

\author{
Harm Kuper ${ }^{1,2}$
}

Received: 1 June 2020 / Revised: 1 June 2020 / Accepted: 14 June 2020 / Published online: 25 June 2020

(C) The Author(s) 2020

\begin{abstract}
The following article is based on the observation that digitalisation in the world of work does on the one hand trigger processes of change, leading to shifts and new constellations in the required qualifications. On the other hand, the effects of digitalisation on qualification requirements are moderated by work organisation. Against the background of a generalist understanding of academic and vocational qualifications, the article deals with the question what curricula correspond to the changing requirements of digitalisation under the new organizational circumstances of Industry 4.0. Turning to the discussion of preparatory qualifications for occupations in Industry 4.0, it follows the hypothesis that the technological developments that lead to a change in qualification needs also increase the potential to meet those needs. This leads to the idea of a digital signature pedagogy.
\end{abstract}

\section{Introduction}

Digitalisation is undoubtedly a societal mega-trend. Many scientific observers stress its hugely transformative, even disruptive power. Nevertheless, the unpredictability of concrete changes triggered by digitalisation is repeatedly pointed out. The changes began with a shift from analogue techniques for information storage and processing to digital ones. However, digitalisation soon became a signature of societal transformation, triggered by technological innovation. Compound words in which digital- (cyber-; e-) is added to conventional terms to turn them into digital-economy or digital-learning characterise the societal transformation of digitalisation. At the

Harm Kuper

harm.kuper@fu-berlin.de

1 Department of Educational Science and Psychology, Freie Universität Berlin, 14195 Berlin, Germany

2 College of Education, Zhejiang University, Hangzhou, China 
same time, the question of what distinguishes a digital from an analogue world and how we can prepare for the change is becoming increasingly pressing.

From a constructivist perspective (Poerksen 2006), the description and analysis of the social world created under the influence of digitalisation depends on the observer's position and the focus of observation. For example, the conceptual distinction between analogue and digital communication brings the acceleration of information processing and its decoupling from spatial and temporal limitations into focus as social challenges. At the same time, however, such a perspective also highlights the possibilities of innovation. For example, the digitalisation of communication-precisely because it reorders temporal and spatial limitations-offers options for coupling traditionally separate domains. Thus, digitalised communication media can be used to develop links between industrial work and vocational learning that are not available with analogue communication. This opens up another aspect of a constructivist view: It is not only the analysis of the social world and its changes but also the identification of possibilities for shaping it that depend on the observer's perspective and the conceptual distinctions used.

The following article is based on the observation that digitalisation in the world of work does on the one hand trigger processes of change with a high momentum of their own, leading to shifts and new constellations in the required qualifications. On the other hand, the effects of digitalisation on qualification requirements are moderated by work organisation. This is where an aspect of design comes into play that is also important for questions regarding the coupling of work and qualifications. In addition, the question will arise to what extent digitalisation can help to develop the endogenous potential of institutions of employment-related academic education and vocational education to promote the necessary qualifications.

\section{Qualifications and organisation in Industry 4.0}

The changes currently discussed under the heading Industry 4.0 or fourth industrial revolution arose from technological innovations, as did the three previous industrial revolutions (cf. Neuburger 2019). The first industrial revolution was characterised by the introduction of new technologies for energy generation-particularly steam engines-which first made mechanisation of production possible. The second industrial revolution was also based on innovations in energy supply. The availability of electrical energy was the technical prerequisite for the introduction of industrial mass production based on the division of labour. The third industrial revolution brought innovative impulses for controlling production on the basis of computer technologies. It was decisive for the implementation of automation. Finally, the fourth industrial revolution is based on technological innovations in digitalisation which change the interfaces between human labour and computer-controlled processes. They are realised in cyber-physical systems (CPS), in which process control and monitoring are redefined not only in terms of the division of human labour but also the division of labour between man and machine.

With regard to qualifications, it is relevant to look at the historical sequence of industrial revolutions since each of these phases of change had considerable 
consequences for human labour in production. How work is designed, in terms of its differentiation, specialisation and controllability, is moderated by the operational organisation of production and communication processes. In the early phases of industrialisation, a form of technical determinism still prevailed, according to which the technological possibilities of increasing performance in production determined its organisational form. This determinism finds prominent expression in Taylor's approach of 'scientific management' (cf. Kieser 2001). It promotes optimum performance for a work organisation where human labour is approximated to machine production by standardising the smallest work steps and subjecting them to hierarchical control. The separation of unqualified operative work and qualified planning work is based on this organisational principle. In this context, two aspects become increasingly clear in the further course of industrialisation. Firstly, the importance of qualified skilled work, with which a minimum level of action planning, coordination and thus flexibility is guaranteed even for operative tasks. Secondly, the dependence of the qualifying or de-qualifying effects of work on the organisation of work. The discussion about qualifications is particularly stimulated by the contrast between industrial and handcrafted work. The latter has a concept of integrating planning, operative and evaluating tasks based on qualifying work experience. This concept has been considered in the European history of the organisation of industrial work (cf. Lane 1989).

The developing technical possibilities are constantly changing the conditions of work organisation and the implementation of qualified work. This became very evident in the course of the third industrial revolution, during which the automation of production began. In automated production, the proportion of human labour involved in the manufacture of a product decreases and the proportion of work performed by machines increases. This shifts the use of human labour to the setting up, maintenance and control of machines (cf. Kieser 2001, 181). This development was initially welcomed as the 'end of the division of labour' (cf. Kern and Schumann 1984). It was expected that there would be a decline in standardised and unqualified operative work on the product and an increase in work on the machines that required qualifications of a more complex and demanding nature. Empirical studies (cf. loc. cit.) showed a more differentiated picture. Admittedly, there was an observable increase in activities whose performance required comprehensive qualifications and independent action. However, even under the conditions of automation, a large percentage of industrial jobs involved standardised and repetitive tasks which did not require or promote any specific vocational qualification. This fact is discussed under the heading of polarisation. The polarisation thesis underlines the moderating influence of work organisation on the effects which technical innovations have on qualifications. It is the basis for key assumptions employed in the discussion of the consequences of a fourth industrial revolution for the relationship between work organisation and qualifications.

As with every previous change in the technological conditions of work organisation, digitalisation brings with it both fears and hopes. The fears are particularly related to scenarios where simple activities are substituted by new technologies (cf. Hirsch-Kreinsen and Ittermann 2019). People who are already disadvantaged on the labour market, with minimal or no vocational qualifications, might be exposed to 
increased risks of unemployment. These would be triggered by the takeover of simple activities, such as the operation and loading of machines as well as simple activities in logistics, by digitally controlled technologies. It is estimated that approximately 15 percent of all employed persons in Germany perform simple tasks such as these. Hopes also arise from the idea of substituting machines in simple, monotonous tasks, but the assumption is that the work of people who have thus far carried out these activities is upgraded in terms of the qualifications needed. The possibilities of a decline in simple, extremely standardised and low-skilled routine activities in favour of more highly skilled, non-routine work are considered under the heading of humane work design (cf. Rothe et al. 2019). In occupational science there is no doubt that the organisational design of work has a decisive influence on which scenario prevails, whether human labour is devaluated or upgraded. It is also realistically assumed that there will be a considerable contextual influence, such as sector affiliation and regional economic development, under which digitalisation will have a diversifying effect on the qualification requirements of industrial work.

Although the effects of digitalisation on qualification requirements are only evident in the way work organisation is resolved, and the fourth industrial revolution is often described as a fuzzy concept whose concrete consequences are not foreseeable, certain technological capabilities are the focus of attention. They concern in particular the exchange of information and data as well as communication. This is a significant difference from the technological innovations of a first generation of computerised industrial work. The latter concerned in particular the control of automated production by computers. Digitalisation concerns the flow of control-relevant information in industrial process chains (cf. Neuburger 2019, p.591). Digitalised process chains are characterised by network-like organisations. They include, for example, concepts in which contacts to customers, suppliers and logistics are linked together informationally. In this way, information on specific requirements or expectations of production can be fed into the process chains. The focus is then less on the separated responsibilities of individual units in the structure of an organisation and more on the sequence of events in their processes. Networking includes connections between machines as well as the connection between people and machines. In the case of the connection between machines, reference is often made to the concept of the Internet of Things, in which, for example, any necessary maintenance or loading of a machine is automatically triggered and carried out by other machines. The variable that is interesting from an organisational point of view is the capacity of machine systems to react independently to variable circumstances. Human-machine interaction is discussed under the heading of cyber-physical systems. Significant criteria for the design of human-machine interaction in work processes are the speed and data capture in the provision of information by new information technologies, as well as the decoupling of communication from constraints of space and time. On the technical side this corresponds to the process of generating, storing and transmitting data, on the human side it is the selection, evaluation and use of information.

The consequences of these changes for qualification requirements in industry are very difficult to assess so far. This is particularly true since specific applications are establishing themselves at very different speeds in the various sectors and economic regions. The extent to which changes in tools, work equipment and 
communication media have an impact on the required vocational qualifications could only be assessable in the context of the respective stages in (vocational) professional development. Classifications that offer a framework for work-related qualifications under the developing conditions of industrialisation have proven to be helpful in this situation. These classifications can be used to place the widely varying requirement structures into a basic framework. Such a classification can be based on the assumption of an increasing abstraction of industrial work from the primary processes of manufacturing a product or providing a service (cf. Hirsch-Kreinsen 2015). In the case of the production of material goods, the qualifications required to master primary processes relate to the nature of the material and the use of tools to transform this material into objects. An example of this is the processing of wood into a piece of furniture. With automation comes an abstraction in which the primary processes are largely taken over by machines. The qualifications thus differentiate themselves in the area of the secondary processes of construction, furnishing, control, monitoring and operation of the machines. The fourth industrial revolution creates a level of tertiary processes where the automated procedures of production are embedded in a network of digitalised communication. Here the establishment and use of digital communication media and of digitalised information are the areas that set new requirements for qualifications. New qualification requirements in this phase of industrial development are related to participation in digitalised communication. In view of the density and speed of information flows, receptive and productive communication behaviour becomes a particular challenge with regard to decisions in industrial process chains.

One subject of future occupational science and qualification analyses concerns the extent to which qualifications are separated along the distinction between primary, secondary and tertiary processes. Already with automation, the use and also the attainment of qualifications concerning the primary process are decoupled from the operative processes of industrial production. These qualifications materialise in the construction of production machines. Qualifications at the level of secondary processes are differentiated according to design, scheduling, maintenance, monitoring and operative tasks in the automation itself. The extent to which qualifications at the primary and secondary levels merge or separate depends on the degree of automation. So far it is not foreseeable whether the qualification requirements under the influence of digitalisation will lead to a similar differentiation along primary, secondary and now also tertiary processes, as was observed with automation. Thus far, expectations of the effects on qualifications often remain vague or are cautiously formulated (e.g. Hirsch-Kreinsen 2015). This is based on changes in controlling activities in the process chains, accompanied by an increase in how demanding they are, as well as in the coordinating activities, for example in the interaction between production, logistics, delivery and collection. With regard to the management of digitalised industry, an increase in decentralised responsibility and a reduction in hierarchical structures are becoming apparent. Decisions on the allocation and selection of (digitalised) information for the positions along an industrial supply chain will remain a central management responsibility. Generalised descriptions of new qualification requirements name the understanding of complex technical systems, 
cognitive resources for the self-organised perception of responsibility in these systems and adaptive as well as creative skills (cf. Stich et al. 2015).

Organisation has a moderating influence on what consequences digitalisation has on qualifications. This results from the linking of the level of professional standards that tasks have with the differentiation between management responsibility on the one hand and operative work on the other. Model conceptions in this respect are still partly oriented towards the changes in organisation in the automation phase. A polarisation of qualification requirements in operational work organisation is therefore also expected to be a dominant pattern under the conditions of digitalisation. Polarisation means a clear separation of coordinating and operating activities. While in this model the coordinating activities are based on specific qualifications acquired in academic or vocational training courses, the qualification requirements for operative work are assumed to be at a low level. When specifying activities that require higher levels of qualification, the question arises as to the importance of professional expertise on the one hand or expertise for cross-sectional tasks on the other; for example, in connection with setting up IT systems. In a polarised organisation, positions differ not only in their qualification requirements but also in the chances for further developing qualifications in the work process. There is the risk of an increasingly divergent qualification of coordinating and operating activities. In connection with digitalisation, 'crowd organisation' is discussed as an organisational alternative to polarisation (cf. Hirsch-Kreinsen and Hompel 2017). Compared to the polarised organisation, it is characterised by a higher degree of flexibility and a correspondingly reduced degree of hierarchy. The model assumptions for crowd organisation assume that expertise from different disciplines is combined and used in specific tasks in changing projects. Here, the dominant idea is not only one of an activity largely supported by academic and vocational competence but also one which envisages the development of these competencies through the work.

Here, two further aspects arise for work qualifications under Industry 4.0 conditions. The first relates to the professional or academic qualification requirements that are necessary to have a chance of becoming an expert in a digitalised work activity. The second concerns the chances to further develop personal qualifications in the work activity itself.

\section{Academic and vocational qualifications for Industry 4.0}

Since the beginning of industrialisation, technological and organisational transformation have been drivers of change in academic and vocational qualifications for work. The two qualification paths differ fundamentally in terms of their curricular foundation and their link to practical work. Academic training programmes for practical occupations build on discipline-based scientific knowledge that leads to technological applications. However, vocational training programmes-at least in Germany-are linked to the practical activity itself and so follow curricula that include both technical knowledge and practical applications. What both programmes have in common is their claim to provide a comprehensive professional foundation that enables further specialisation. This generalist approach to vocational education avoids 
too close a coupling to the specific requirements of a particular activity, which always entails a limitation of the qualification possibilities in the work. The aim is rather to enable persons with generalist qualifications to meet the qualification requirements of a wide range of activities in a professionally competent manner and to develop their expertise further in the course of their work.

Against the background of this rough sketch of a generalist understanding of academic and vocational qualifications, the question arises as to what significance will be assigned in the corresponding curricula to the requirements of digitalisation. There is broad agreement professions and occupations will change under the challenges of digitalisation, but will certainly continue to determine the basic framework of qualifications for jobs in the digitalised industry (cf. Stich et al. 2015). This assessment reflects not only confidence in the flexibility of academic and vocational training programmes but also the conviction that digitalisation in industry can only be implemented by combining it with basic professional and vocational skills. An overview (cf. VDMA 2016) of the technological developments in the course of Industry 4.0 clearly shows that digitalisation is linked to existing concepts, e.g. in manufacturing technology, production logistics or corporate communication. This is accompanied by the widespread assessment that digitalisation is more of an evolutionary than a revolutionary change in industrial organisation. It also affects the dynamics of change in academic and vocational qualifications (cf. Wilbers 2017). It is still too early for findings from empirical research on change in education programmes. However, there are results from exploratory surveys that estimate the consequences for training courses of changing qualification requirements (cf. Heidling et al. 2019). In this respect, the most important component in the training of engineers continues to be the undergraduate course anchored in the traditional engineering sciences with the objective of teaching engineering fundamentals and methods. Supplementing or revising traditional curricula is largely deemed an appropriate means of meeting the curricular requirements that result from digitalisation. Combined courses of study and study programmes for engineers already in employment are also considered appropriate.

Overall, however, the findings very clearly indicate that the professional requirements of digitalisation require not so much independent expertise as a supplement to the technical expertise already available. These findings are underlined by the fact that many of the qualifications that are considered necessary in addition to engineering qualifications are not technical in nature. For example, more than half of the companies surveyed in the automation technology sector will expect their engineers to have skills in the areas of data security, data management and user interfaces. It is a common assessment in the automation industry that engineering courses of study should increasingly integrate practical professional elements in addition to their disciplinary foundation. The combination of theory-based knowledge with practical experience, for example in the context of a 'dual study' programme, is also to be understood as a response to the prevailing uncertainties in industry about

\footnotetext{
1 duales Studium: a 'dual study' programme in Germany combines a degree programme with vocational training.
} 
the effects of digitalisation. The consequences, for example on communication processes between customers, suppliers and manufacturers, are still considered too unpredictable to be able to determine basic professional competence requirements. On the other hand, the coupling of qualification attainment and practical application of the qualification in a developing field promises that demand for and provision of qualifications will experience co-evolutionary growth at the interface of technology development and its social conditions.

In principle, the assessments that apply to vocational training below academic level are similar to those for the academic preparation of professions. For these occupations, too, the upcoming changes are seen primarily in the area of organisational change. The main focus are considerations of changing business models, product and process innovations as well as employment relationships in digitalised industry (cf. Wilbers 2017). Consequently, considerations of the consequences for vocational training in the 'dual' system focus less on specific IT skills and more on the handling and competent use of digitalised technologies in a changed world of work. Here, too, predictions regarding the concrete development of qualification requirements are uncertain. Surveys conducted in industry (cf. Pfeiffer et al. 2016) show, however, that industry representatives in the technical occupations continue to rely on established vocational training and see the skills imparted there as the basis for practical work in a digitalised working environment. In view of that, no new occupations are required, but additions to the curricula for training the existing occupations are necessary. For other occupational fields-such as commercial occupations - the level of analysis is seen as less developed (cf. Wilbers 2017).

Industry's clear preference for qualification concepts that integrate aspects of digitalisation into existing vocational and academic training programmes leads to the question of how this can be achieved.

\section{Digitalisation of training programmes for occupations in Industry 4.0}

Turning to the discussion of preparatory qualifications for occupations in Industry 4.0 , one quickly gets the impression that the technological developments that lead to a change in qualification needs also increase the potential to meet those needs. On the surface, considerations on vocational training 4.0 or university teaching 4.0 bear witness to this. But here, too, appendix 4.0 signals innovation needs that in many cases still require conceptual design.

It is assumed that the sphere of vocational education is more open to digital teaching-learning scenarios than general school education. For school education, there is criticism not only of the low levels of digital media participation but also of the conceptually underdeveloped usage. In many cases, the use of digital media is limited to the provision of material and presentations (cf. Eickelmann et al. 2014, 204 et seq.) In vocational education, by contrast, the integration of digital media is considered to be well developed in many areas. This results firstly from the fact that skills should be acquired in dealing with specific technical systems that are themselves digitalised. Thus, digitalisation already has an influence on vocational education via the learning objectives. Much more developed here too, however, are digital educational 
technologies that enable problem-oriented learning processes, learning management systems, simulations or virtual experiments, for example. Against this background, the confident and mature use of digital educational technologies is becoming an overarching goal of vocational education (cf. Eder 2015).

In vocational education, digitalisation is creating changed conditions for the discussion about suitable learning locations. A fundamental distinction is made between learning locations that are separate from the work process-mostly schoolbased-and work-integrated learning locations. With digitalisation, formats that rely more on the self-direction of learners are valued more highly than ones which require the traditional classroom teaching-learning interaction. Work-integrated learning locations and variants of informal learning are gaining greater conceptual significance. In light of this, there is a greater chance that embedding the acquisition of vocational competence within the working environment and aligning it to specific work tasks will help to avoid the losses that can occur in the transfer from school-based learning environments to places of application (cf. Schuh et al. 2015). An example might be digital user interfaces for production machines that provide workers with information and instructions on the work steps. Such applications can also be enhanced by error warnings, accompanied by hints on the correct operation of the machine and on error prevention. These examples of the design of learning environments are closely linked to work processes and directly integrated into the characteristics of Industry 4.0. On the one hand, they show the potential of digitalisation to provide new ways of promoting qualifications at the same time as the requirements for those qualifications change. On the other hand, the question arises whether qualification strategies that are closely linked to specific tasks do not make it more difficult to develop generalist skills that can be transferred to different work requirements. As for the design of work processes in Industry 4.0 itself, man-machine interaction is also proving to be a critical aspect for the integration of learning opportunities in these processes. The complexity of the qualification processes and the range of skills acquired in them will depend on the design of that interaction. This poses challenges for the didactics of vocational education under the influence of digitalisation.

In order to focus on the qualities of work environments that promote learning, classifications are useful for a differentiated presentation of the link between work requirement and learning support. These can draw on the technical potential of digitalisation to design work which promotes learning (cf. Cernavin 2018, p. 300f.). Thus digitalisation has an influence on:

- learning content, by linking it with information on the work process,

- the learning method, by giving the learners opportunities to control the learning process themselves,

- the learning environment, by providing contextual information for the learning process that goes beyond the immediate working environment,

- the learning conditions, by creating opportunities for social interaction and.

- learning development, by recording and reporting learning outcomes and using them to select subsequent learning steps. 
It is also due to its potential for networking that digitalisation is important for the design of working environments that promote learning. With regard to vocational learning, it is important to continue to differentiate between technical and human (socio-cultural) processes, despite the emphasis on human-machine interfaces, and not to misunderstand them as identical despite their link. Cernavin (2018, p. 303 f.) assumes that the dimensions of requirements relevant to vocational activity can be arranged on a continuum of increasing complexity. While he considers technical interpretation patterns to be applicable only up to a certain degree of complexity, he recognises the relevance of socio-cultural interpretation patterns for the entire complexity spectrum of requirements. The lowest degree of complexity is found in actions that are divided into fixed causal successive steps. They can largely be mastered within the framework of technical patterns of interpretation-and consequently within the framework of digitalisation. Technical interpretations are also sufficient for decisions in contingent-i.e. circumstantially varying-requirement situations, provided that adequate information about relevant parameters is available. If, however, creative components such as intention, reflection and emotion are added to the activity requirements, the applicability of technological interpretation patterns disappears, while that of socio-cultural interpretation patterns remains completely intact. The limits of digitalised learning at work thus become visible where decidedly human qualities of action become more important. If decisions have to be made in consideration of the meaningfulness of work, if evaluations of the results of work have to be made or the shaping of interpersonal relationships plays a role, digital systems will have less of a controlling function and at best a supporting function.

In future, academic and vocational training courses that prepare for work in Industry 4.0 and for continued learning in a digitalised environment must also include handling the difference between technical and socio-cultural patterns of interpretation. The prerequisites for this are not limited to the amount of knowledge about technical possibilities. Rather, it is a matter of practical skills and the acquisition of a spectrum of activity models for dealing with digital possibilities for linking work and learning. The attainment and development of this skill itself depends to a large extent on practical exercise. Therefore, one challenge is to understand digital learning in academic and vocational training courses not only in terms of technical support for traditional teaching-learning settings, but also to give curricular importance to the use of digital learning possibilities themselves. Expanding on a thought of Shulman's (cf. 2005), the use of digital learning media can be understood in the sense of a 'signature pedagogy', i.e. as a type of teaching that already involves preparation in the practical thinking and action that characterises later vocational requirements. To illustrate this, elements of such a digital signature pedagogy will be outlined here through digital teaching-learning settings in academic courses:

The most widespread format of digital academic teaching is probably the Massive Open Online Course (MOOC). In its basic form, lectures are filmed and made accessible online. The format thus follows the principles of digitalisation, which aim to open up access to information and participation in communication independent of time and place. This is also where its potential for a digital signature pedagogy lies-MOOCs require the participants to independently pace their learning process following a specified didactic content structure. The format thus opens up initial 
experiences with self-directed learning, which can be supplemented by additional elements such as self-tests or participation in online discussion groups. For the development of digital competences it is also important to compare learning experiences in MOOCs with experiences from traditional classroom lectures.

The webinar format, where participants connect online to discuss theme-centred input, has a much more accentuated focus on the interactive components of learning. The webinar requires a large amount of temporal coordination and participation in real time, but opens up a high degree of freedom in terms of connectivity across geographical distances. The digital signature pedagogy is a result of the particular demands on participation, where the digital format demands independent regulation of attention to a much greater extent than in face-to-face seminars and where a combination of oral and written forms of expression is required. In addition, the format invites students to research information online parallel to their interaction with the other participants and to introduce it into the discussion in a targeted manner. A comparative assessment between digital webinars and face-to-face seminars by the learners themselves can pertain in particular to the form of their own role in the interaction.

Projects or research workshops conducted online require a very strong personal contribution in the structuring of learning processes by the learners themselves (cf. Toelch and Ostwald 2018). Here digital platforms are used to coordinate a project's work steps among the participants, to document results and to obtain advice. The signature pedagogies feature productive learning steps far more than receptive ones. Decisions regarding the productive use of digital media lie with the learners themselves and include aspects from the selection of interaction partners to the appropriate presentation of the structure of a project and, if necessary, to data management and the publication of the project results. A significant difference to analogous forms of project communication may arise in questions related to the specification of access rights to project-relevant information for the individual participants.

\section{Conclusion}

Digitalisation is driving the transition to Industry 4.0. The resulting demands on work are moderated by their organisation. This applies to key qualifications, such as communication, the assumption of responsibility, or the use and generation of information, even more than technological qualifications. Particular attention is paid to the potential for networking between people and between people and machines. Digitalisation in industry is not only changing work and work demands, but also the possibilities of combining work with job-related learning. For vocational and academic education programmes, this creates the challenge of preparing students to be competent users of digital media at the same time as preparing them for their professional activities. The digitalisation of vocational and academic education is thus more than a conversion of teaching-learning scenarios from analogue to digital media - it can, in the sense of the concept of digital signature pedagogies, form the starting point for developing competences for the use of digital media at work and in lifelong learning based on the experiences with digital learning media. The digital 
integration of work and learning would thus become a co-evolutionary process, the beginnings of which we can now shape.

Acknowledgements Open Access funding provided by Projekt DEAL.

Open Access This article is licensed under a Creative Commons Attribution 4.0 International License, which permits use, sharing, adaptation, distribution and reproduction in any medium or format, as long as you give appropriate credit to the original author(s) and the source, provide a link to the Creative Commons licence, and indicate if changes were made. The images or other third party material in this article are included in the article's Creative Commons licence, unless indicated otherwise in a credit line to the material. If material is not included in the article's Creative Commons licence and your intended use is not permitted by statutory regulation or exceeds the permitted use, you will need to obtain permission directly from the copyright holder. To view a copy of this licence, visit http://creativecommons.org/licen ses/by/4.0/.

\section{References}

Cernavin, O. (2018). Ansätze für eine lernförderliche Arbeitsgestaltung 4.0. Zeitschrift für Arbeitsforschung, 27(4), 295-315.

Eder, A. (2015). Akzeptanz von Bildungstechnologien in der gewerblich-technischen Berufsbildung vor dem Hintergrund von Industrie 4.0. Journal of Technical Education, 3(2), 19-44.

Eickelmann, B., Schaumburg, H., Drossel, K., \& Lorenz, R. (2014). Schulische Nutzung von neuen Technologien in Deutschland im internationalen Vergleich. In W. Bos, et al. (Eds.), ICILS 2013Computer- und informationsbezogene Kompetenzen von Schülerinnen und Schülern in der 8. Jahrgangsstufe im internationalen Vergleich (pp. 197-229). Münster: Waxmann.

Heidling, E., Mail, P., Neumer, J., Porschen-Hueck, S., Schmiel, K., Sopp, P., et al. (2019). Ingenieurinnen und Ingenieure für Industrie 4.0. München: IMPLUS-Stiftung.

Hirsch-Kreinsen, H. (2015). Einleitung: Digitalisierung industrieller Arbeit. In H. Hirsch-Kreinsen, P. Ittermann, \& J. Niehaus (Eds.), Digitalisierung industrieller Arbeit (pp. 10-31). Baden-Baden: Nomos.

Hirsch-Kreinsen, H., \& Ittermann, P. (2019). Digitalisierung industrieller Einfacharbeit. In R. Dobischat, et al. (Eds.), Bildung 2.1 für Arbeit 4.0? (pp. 99-117). Wiesbaden: Springer Fachmedien.

Hirsch-Kreinsen, H., \& ten Hompel, M. (2017). Digitalisierung industrieller Arbeit: Entwicklungsperspektiven und Gestaltungsgegensätze. In B. Vogel-Heuser, et al. (Eds.), Handbuch Industrie 4.0 (pp. 357-376). Berlin: Springer.

Lane, C. (1989). Management and Labor in Europe. Aldershot: Edward Elgar Pub.

Kern, H., \& Schumann, M. (1984). Das Ende der Arbeitsteilung? Rationalisierung in der industriellen Produktion. München: Beck.

Kieser, A. (2001). Organisationstheorien. Stuttgart: Kohlhammer.

Neuburger, R. (2019). Der Wandel der Arbeitswelt in einer Industrie 4.0. In R. Obermaier (Ed.), Handbuch Industrie 4.0 und Digitale Transformation (pp. 589-608). Wiesbaden: Springer Fachmedien.

Pfeiffer, S., Lee, H., Zirnig, C., \& Suphan, A. (2016). Industrie 4.0-Qualifizierung 2025. Studieim Auftrag des VDMA (Verband Deutscher Maschinen- und Anlagenbau). Frankfurt a.M.: VDMA.

Poerksen, B. (2006). Digital distinctions. An analytical method for the observation of the WWW and the emerging world of communication. Contructivist Foundations, 2(1), 17-27.

Rothe, I., Wischniewski, S., Tegtmeier, P., \& Tisch, A. (2019). Arbeiten in der digitalen Transformation-Chancen und Risiken für die menschengerechte Arbeitsgestaltung. Zeitschrift für Arbeitswissenschaft, 73, 246-251.

Schuh, G., Gartzen, T., Rodenhauer, T., \& Marks, A. (2015). Promoting work-based learning through Industry 4.0. Procedia CIRP, 32, 82-87.

Shulman, L. (2005). Signature pedagogies in the professions. Daedalus, 3, 134.

Stich, V., Gudergan, G., \& Senderek, R. (2015). Arbeiten und Lernen in der digitalisierten Welt. In H. Hirsch-Kreinsen, P. Ittermann, \& J. Niehaus (Eds.), Digitalisierung industrieller Arbeit (pp. 143172). Baden-Baden: Nomos. 
Toelch, U., \& Ostwald, D. (2018). Digital open science-Teaching digital tools for reproducible and transparent research. PLoS Biol. https://doi.org/10.1371/journal.pbio.2006022.

VDMA (Verband Deutscher Maschinen- und Anlagenbau) (2016). Industrie-4.0-Forschung an deutschen Forschungsinstituten. Frankfurt a.M.: VDMA

Wilbers, K. (2017). Industrie 4.0. Herausforderungen für die kaufmännische bildung. Berlin: epubli

Publisher's Note Springer Nature remains neutral with regard to jurisdictional claims in published maps and institutional affiliations. 